This item was submitted to Loughborough's Research Repository by the author.

Items in Figshare are protected by copyright, with all rights reserved, unless otherwise indicated.

\title{
Managing value and quality in design
}

PLEASE CITE THE PUBLISHED VERSION

PUBLISHER

(C) Taylor \& Francis

LICENCE

CC BY-NC-ND 4.0

\section{REPOSITORY RECORD}

Thomson, Derek S., Simon A. Austin, Hannah Devine-Wright, and Grant R. Mills. 2019. "Managing Value and Quality in Design". figshare. https://hdl.handle.net/2134/3870. 
This item was submitted to Loughborough's Institutional Repository (https://dspace.lboro.ac.uk/) by the author and is made available under the following Creative Commons Licence conditions.

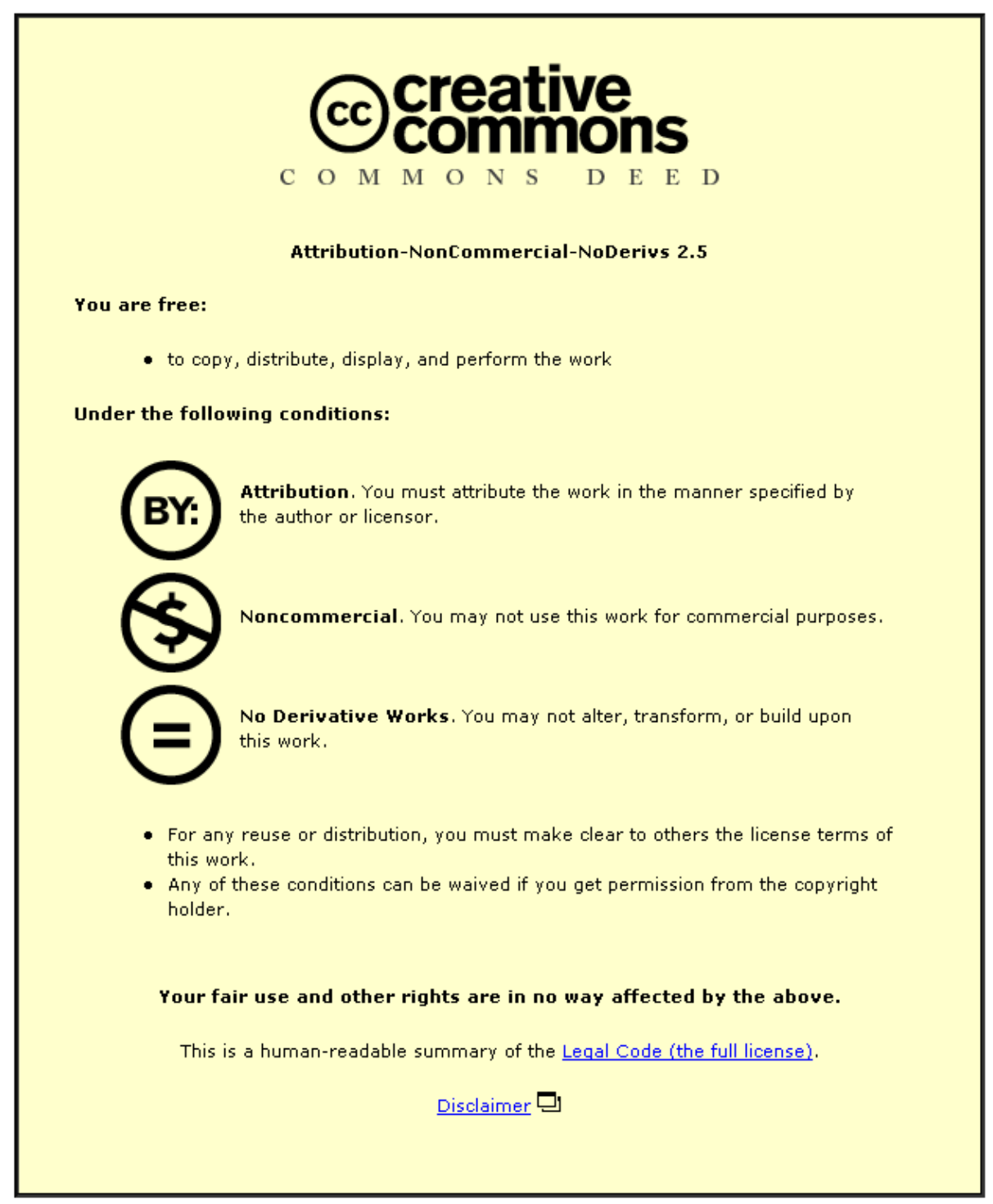

For the full text of this licence, please go to: http://creativecommons.org/licenses/by-nc-nd/2.5/ 


\title{
Managing Value and Quality in Design
}

\begin{abstract}
This paper focuses on the role of stakeholders in defining project values, which in turn influence product quality expectations, and of designers in meeting these goals. Ultimately, these determine the functional, physical and symbolic product characteristics that are necessary to achieve customer satisfaction.
\end{abstract}

The issues of value and quality are compared within the context of design management, including their theoretical and philosophical underpinnings as well as current management techniques. Value and quality can be misunderstood and confused; the authors suggest that it is vital for stakeholders to have a common understanding of terminology and meaning. This is particularly true of customers who need to be engaged in a straightforward manner.

We describe our research into the management of value delivery in design and explore opportunities for incorporating design quality indicator (DQI) assessments. The paper discusses how the DQI can form part of a project management system that ensures the delivery of stakeholder value during the design stage. Opportunities for customisation of the DQI content and the context of application at this stage of a project (as opposed to assessments during and after construction) are explored and may be key to success in delivering value in addition to product quality.

\section{Keywords}

Quality; Qualities; Value; Values; Design; Management; Customer Satisfaction; Design Quality Indicator 
To what end does the construction industry design? What does it seek to achieve when developing design solutions? How important are the values and opinions of its stakeholders and how does it know when it is responding to their needs? This paper and associated research ${ }^{1}$ addresses these issues.

The construction industry needs to engage stakeholders in a dialogue of value delivery to understand what they need from their products. This analysis must extend the investigation of business or functional need as practised in value management (Ashworth and Hogg, 2000; Neasby et al., 1999; Kelly and Male, 2002) to expose stakeholders' personal values which are reflected in their beliefs, attitudes and behaviours. These values frame their view of the world, including construction products.

This paper investigates the role of dialogue with stakeholders during design and the need:

(i) for a common understanding of quality and value;

(ii) to educate the industry and its customers in the provisions of value; and

(iii) to develop means of framing design activity so that the delivery of value can be monitored and managed.

We describe the potential of the Design Quality Indicator to assist in the design of construction products that will be perceived to be of value by their stakeholders. This necessitates investigation of the terms quality, qualities, value and values. We derive the meaning of these terms from first principles to establish a foundation for the development of design methods that can respond to construction industry customers in the age of the experience economy. Future directions for the practical implementation of such methods are identified.

The authors suggest that value delivery should be a fundamental objective for all construction projects. Solutions must be developed to explicitly respond to common values, and the Design Quality Indicator could serve a useful role. The benefits of such an approach are evident within the industry. CABE (2002a) illustrated the impact of good design on improving the quality of life in schools, businesses, housing and in urban settings. The impact of design on the value of a construction product can offer has been summarised by Lipton (2001), who stated:

\footnotetext{
${ }^{1}$ See www.valueindesign.com
} 
"Design represents a minute proportion of the lifetime cost of a building - less than 1 per cent - but done well it has a disproportionate impact on how well the building, and its surroundings, perform.”

To this end, the need to "exploit the economic and social value of good design to improve both the functionality and enjoyment for its end users of the environments it creates" is an objective of the Strategic Forum for Construction (2002).

2 The Timeliness of Value

New interpretations of value are beginning to emerge in construction. For example, when Spencer and Winch (2002) commented that:

"[The] creation of new value is two-dimensional, beginning with the actual design and construction of the asset itself, and resulting in the production of an asset that is exploited as a medium for an organisation to create its own value”

They identified the context in which value is perceived: as people interact with the products of construction. Evidence of the benefits of what buildings can do for their occupiers is beginning to emerge, for example, Luxton (2002) found a 120\% reduction in staff turnover in a call centre occupying a building specifically designed to create a sense of community and place through informal meeting places and innovative building structure solutions.

Saxon (2002a) recently expanded the ratio of whole life costs proposed by Evans et al. (1998) to demonstrate the impact of building design on business costs and, more significantly, on business performance. Presenting at the recent launch of the 'Be' construction industry body, Saxon highlighted the critical role of quality of the environment created by buildings on employees and, consequentially, business performance (Table 1). The value brought by buildings to businesses is thus significantly more than their traditional written-down, capital asset value.

\section{[TABLE 1]}

Government and industry initiatives are also championing the cause of focusing on customer value. The Accelerating Change (Strategic Forum for Construction, op. cit.) agenda is "for the UK construction industry to realise maximum value for all clients, end users and stakeholders and exceed their expectations through the consistent delivery of world class products and services.” The report identifies 
the role of value delivery in promoting the quality of life by stating that the UK construction industry

must:

“exploit the economic and social value of good design to improve both the functionality and enjoyment for its end users of the environments it creates (for example, hospitals where patients recover more quickly, schools and work places which are more productive and more enjoyable to work in, and housing which raises the spirits and enhances the sense of self worth).”

Tony Blair has made a similar case for Better Public Buildings to improve the quality of life (Department for Culture, Media and Sport, 2000) but the industry has a long way to go: the Chairman of Collaboration for the Built Environment (Be - formed by the merger of the Design Build Foundation and Reading Construction Forum) has recently stated that the industry "knows little of how it adds value to customers or society” (Saxon, 2002b) and that:

“Good 'people policies' will drive thinking on how things are to be done. The key to the set, in our view, is to create and capture far more customer value thus providing, the resources for all other improvements.”

It will not be sufficient for UK construction to respond to the values of its immediate customers. It must also reflect broader societal values in its work and appreciate its role as a creator of places, not just a provider of buildings.

To this end, it is important that the industry understands how quality and value relate to people: how society perceives the social benefit (or otherwise) of its activity. This paper aims to provide a step in developing this understanding.

3

\section{Quality Principles}

\subsection{Qualities}

People and products possess qualities, some of which may be desired and others not. The idea that qualities are the physical or functional attributes of a product is reinforced by the JIS for QC (Magrab, 1997), which defines quality as the totality of the characteristics and performance that can be used to determine whether or not a product or service fulfils its intended application.

Cargile (1995) observed that “we could, in everyday usage, substitute 'features', 'properties', 'traits', ‘characteristics’, ‘attributes’, and some other terms for ‘qualities'.” He continued to note that “a quality 
can be attributed to a number of things, truly or falsely.” This implies that quality assessments may consider qualities inherent in objects, allowing these judgements to provide a measure of quality, rather than to solely rely on the direct measurement of physical or functional characteristics. These are the product qualities which, when measured, can help in the assessment of quality and value.

Current methods of delivering ‘quality' do not seek to ensure that qualities which response to the customer's values are embedded in a product or service. Quality Control, for example, is merely concerned with demonstrating consistency in the product qualities delivered from manufacturing processes, but does not question the appropriateness of the qualities themselves. Quality Assurance seeks similar consistency in service provision. Total Quality Management goes some way towards linking the qualities sought in a service provision with the expectations of the service consumer, but does not directly relate the consumer's perception of service quality to service qualities.

Product qualities are the facts of the matter. Their relation to the qualities sought by users is reflected in the assessment of product quality. The qualities sought by users are, in turn, a result of their values - their beliefs about what ought to be. In a review of historical quality initiatives, Gale (1994) noted the lack of direct investigation of the customer values. He argues that, if these values fundamentally influence how quality is perceived, they should be assessed and coined the term Customer Value Management.

\subsection{Quality}

This section explains the difference between product qualities and the perception of product quality formed by experiencing these qualities. In the construction industry, quality is associated with competency and proficiency levels (in materials selection, workmanship, design detail, and so forth) as a route to customer satisfaction. Snagging lists ('deficiency lists' in North America) are a common means of addressing quality but also represent a failure, as they are a response to defects. Broader business interpretations are also common in construction, with quality assurance accreditation being prominent and, for some customers, a prerequisite to engagement. Some benchmarking initiatives involve an internal measurement of the quality of processes, gathered for the benefit of the provider rather than its customer. The prevalent view is that compliance with performance levels promotes construction business quality.

A range of lean approaches has been adopted by manufacturing organisations in their pursuit of efficiency, many of which also have quality benefits. The principles Kaizen (continuous improvement) 
and Poka Yoke (getting it right first time) reduce defects with product or service quality implications and Six Sigma, promotes quality in process improvement.

Each quality camp harbours its own definition of quality. For example Juran and Godfrey (1999) provided two definitions:

'Quality means those features of products which meet customer needs and therefore provide customer satisfaction. ... Higher quality in this sense usually costs more.”

and

“Quality means freedom from deficiencies. ... Higher quality [in this sense] usually costs less.”

A prominent view of quality in construction is associated with quality management systems, rather than the measurement of products for compliance with specification. The treatment of quality therefore required from this investigation must also be associated with the quality management, rather than measurement, view.

EN ISO 9000 and BS 4778 (BSI, 2000, 1991) have similar views of quality, the latter defining it as an “inherent characteristic of a product, process or system related to a requirement.” Burt (1978) adopted this view in the context of construction products:

"The totality of the attributes of a building that enable it to satisfy needs, including the way in which individual attributes (external; performance; aesthetics and amenity) are related, balanced and integrated in the whole building and its surroundings.”

In summary, the quality of a product is an assessment of how well its qualities (that is its features or attributes) meet the customer's needs. This assessment can be performed mechanistically or numerically, as it is an assessment of fact that does not incorporate the judgement or interpretation of an individual.

\section{$4 \quad$ Value Principles}

It is important to distinguish between values and value: again, one is not the plural of the other. Values are inherently subjective because they frame the judgements made by individuals or organisations. Value, on the other hand, relates to assessments about products and can be subjective, if they remain internalised within an individual or an organisation, or objective if they are expressed. In the latter case, value assessment and measurement can inform management action. 


\subsection{Values}

Our values are the principles by which we live. They are the core beliefs, morals and ideals of individuals and are reflected in their attitudes and behaviours in society. Köhler (1966) identified this guiding, ethical role of values by stating 'At the bottom of all human activities are values, the conviction that some things “ought to be.”' Pirsig (1974) commented 'Life would just be living without any values or purpose at all.’ Values also underpin the activities of business organisation (Griseri, 1998). Although values can be complicated and intertwined, they frame the decisions that we make (Keeney, 1998).

Individuals can subscribe to certain common values shared by others (religious or political beliefs, for example). This commonality of values also defines cultures. The values held by individuals influence their perception of the world and, more specifically, their assessment of products and services. Hence, values frame the assessment of value. When individuals collaborate to realise a common goal, projects are formed. A value system can emerge if values are expressed and shared between them.

\subsection{The Nature of Value}

People make value judgements when they assess an object (Fig 1) with regard to their beliefs and expectations. Vickers (1968) noted that these value judgements are intertwined with individuals' cognition of their surroundings and stimulate their actions. Hence, value is a perception. It is not a measurable product attribute, unless the outcome of a value assessment is attributed to products as one of its qualities. In this case, the value represented as one of a product's qualities would be the result of an assessment.

\section{[FIGURE 1 ABOUT HERE]}

Despite its subjective nature, objective interpretations of value are commonplace. The allocation of a monetary sum to express perceived value is a common means of setting the price of a product. When a consumer asks him or herself “is it worth it?” they are making a value judgement in light of their own, often tacit, values and comparing this with the market value assessment (typically expressed as a price).

In this sense, the product is a commodity rather than a reflection of beliefs. In the experience economy, with the need to create buildings that respond to their social context, the subjective approach to understanding the nature of value delivery may be as important. 
Four fields were reviewed to develop an understanding of value that would be useful in construction:

1. the theory and philosophy of value;

2. manufacturing and product design practices such as value analysis, value engineering and lean manufacturing;

3. the recently-emerged field of customer value management; and

4. construction management theory.

Taking a philosophical view, Dent (1995) stated that value comprises:

“... three connected issues: first, on what sort of property or characteristic 'having value' or 'being of value' is; second, on whether having value is an objective or subjective matter, whether value reposes in the object or is a matter of how we feel towards it; third, on trying to say what things have value.”

The manufacturing sector has adopted an objective view of value for many years. Value analysis, for example, involves the testing of functions required by customers as design objectives. This approach substitutes for the direct engagement of customers (to identify their values to which the design must respond) recognising that its success in doing so will be judged subjectively by these customers.

Some discontent with the limitations of the objective view has existed for many years. Miles (1961) suggested that the definition of value should vary with the purpose, viewpoint and intent of the person defining it, given that "value means a great many things to a great many people". He identified four forms: use value, esteem value, cost value, and exchange value, which are still current (SAVE International, 1997). In the context of construction, Best and De Valance (1999) interpreted Miles’ definitions as:

1. Exchange value: the open market price of a building. This is of interest to property developers.

2. Use value: the value of a building to the organisation performing activities within it. This is of particular interest to owner-occupiers.

3. Esteem value: the attractiveness or desirability of a building. This represents the subjective value judgements formed by those influenced by, but not using the building.

Fowler (1990) recognised that a product must fulfil a user's need in order to have value and summarised the relationship: 


$$
\text { Value }=\frac{\text { Worth }}{\text { Cost }}
$$

as being at core of value analysis. However, he recognised the problem of objectively measuring worth and suggested an alternative expression with a more subjective view:

$$
\text { Value }=\frac{\text { User's initial impression }+ \text { Satisfaction in use }}{\text { First cost }+ \text { Follow on costs }}
$$

With the advent of lean manufacturing, Womack and Jones (1996) defined value as “a capability provided to a customer at the right time at an appropriate price, as defined in each case by the customer.” Trischler (1996), meanwhile, defined stakeholder value as "the perceived balance between the things people receive in exchange for the things they must give up to get them.”

In the field of Customer Value Management (CVM), Gale (op. cit.) defined value as quality (including all non-price attributes) relative to price and stated that quality, price, and value are relative. He therefore supports the subjective view of value. This view is sustained by other CVM definitions, which also recognise customer perception. Daniels (2000), for example, defined value as the relationship of marketperceived price to market-perceived quality while Dumond (2000) stated that customer value:

- $\quad$ is linked to the use of a product or service, thereby removing it from personal values;

- $\quad$ is perceived by the customers rather than objectively determined by the seller; and

- $\quad$ typically involves a trade-off between what the customer receives (e.g. quality, benefits, worth) and what he or she gives up to acquire and use a produce of service (e.g. price, sacrifices).

Despite the prevalence of subjective definitions of value, such a viewpoint is not reflected in the current European Standards. BS EN 1325-1 (BSI, 1997) instead adopts an objective stance by defining value as "the relationship between the contribution of the function to the satisfaction of the need and the cost of the function,” implying that value can be measured.

In construction, Dell'Isola (1997) reflected the objective view in the definition:

$$
\text { Value }=\frac{\text { Function }+ \text { Quality }}{\text { Cost }}
$$

while Burt (op. cit.) stated that "maximum value is ... obtained from a required level of quality at least cost, the highest level of quality for a given cost, or from an optimum compromise between the two,” suggesting that a more objective view may also appropriate for construction. Further, CABE (2001) integrate both subjective and objective views by defining value in a construction context as "a measure of 
the worth of something to its owner or any other person who derives benefit from it, this being the amount at which it can be exchanged.”

To sum up, value is the relationship between positive and negative consequences (output and input, or benefits and sacrifices). More specifically:

- Value does not exist it is own right, but is an assessment of an object.

- This assessment occurs in a context, and is framed by characteristics of that context.

- Value assessment can be subjective, when framed against an individual's values, or objective, when the relationship between benefit and expense is compared.

- The expense can be either resource consumption (time, money, people) or emotional effort (stress, attaining and maintaining buy-in).

- $\quad$ Value may be influenced by time at which it is judged or assessed.

In our work we have therefore adopted a working definition of:

$$
\text { Value }=\frac{\text { Benefits }(\text { what you get })}{\text { Sacrifices (what you put in) }}
$$

This broad definition expresses provision of the right thing (product or service), at the right time, for the right consideration, to the right customer.

\section{$5 \quad$ Relating Quality and Value}

\subsection{Relating Qualities to Value Judgements}

The industry needs clear definitions of qualities, quality, value and values. We have suggested that values should follow Köhler’s definition, that is, they are the beliefs of the project team, whilst qualities should represent physical or functional product attributes. Quality should be treated as an objective assessment of the qualities in relation to the project's values.

Value, if treated subjectively, is a judgement by an individual about a product or a service, framed by their values. An objective assessment requires the evaluation and comparison of benefits and sacrifices, with appropriate units of measurement. The specific content of the assessment expression depends in the circumstances of the value assessment. 
Fig 2 illustrates the relationship between the terms recommended for construction, resulting from the above theoretical analysis.

\section{[FIGURE 2]}

\subsection{A Framework of Value and Quality}

The effective management of quality and value in design requires new means of engaging stakeholders in the design process and of structuring that process. A value framework could help stakeholders articulate their values by structuring their discussion. The resulting negotiated project values would in turn determine the qualities required of the emerging product.

In addition to a framework to structure dialogue, a consistent language of value would ensure correct interpretation of discourse between stakeholders and the design team. It could define the common terms related to value perception and delivery. Such a language would, in the first instance, be documented but in the long term become ingrained in industry practice where it be applied to conversations intuitively.

\section{[FIGURE 3]}

Our Framework of Value is shown in Fig 3. It has three overlapping layers, representing values, the project and value. Peoples' values lie at their very core. They are the root beliefs and attitudes that people harbour, which fundamentally influence how they act. Just like people, organisations and wider society also have values. They play a role in defining who and what we are as people, teams, businesses or even societies. The customer's business strategy justifies the creation of the project in the first place, as well as defining what the project must deliver to be successful. However, the strategies of all the businesses involved in a project will play some role in setting overall project direction.

Within the three layers of values, project and value we can identify three interfaces in the problem-setting process:

- $\quad$ Project Values - the negotiated and shared guiding principles to which all stakeholders subscribe.

- $\quad$ Objectives - specific goals that reflect the project values and business strategies.

- $\quad$ Qualities - the product features required to satisfy the objectives.

The framework also shows how we can thing about value being delivered using the terminology of Allinson (1997). Firstly, value is envisioned in the design proposals. It is harnessed in the emerging 
project as it is constructed, and is experienced by users as the product (i.e. a building) is handed over and used.

The last part of the framework suggests how we can generate management information on performance. We suggest that this should address two issues. Firstly, we need to assess the performance of the product (such as finishes, services operation, durability, and so forth) and of the business performed within it. Secondly, we need to assess the performance of the project in reflecting the project values during design and construction and of predicting the product's performance. These two forms of assessment overlap in a region we can identify as product quality and are concerned with determining the extent to which product qualities reflect stakeholders’ values.

The interaction of all the elements is illustrated in Fig 4, which builds upon the theoretical relationships developed earlier (see Fig 2). It shows how both objective and subjective assessments of value are constructed through the ongoing dialogue of stakeholders with the project team and their opinions of the product during its design, manufacture, assembly and use.

\section{[FIGURE 4]}

\subsection{The Role of the Design Quality Indicator}

The Design Quality Indicator (DQI) has been developed as a means of assessing the quality of construction projects (Gann et al., 2003). Its purpose is to structure and summarise stakeholders' assessments of design quality. Repeated assessments compiled using the same structure can be compared over time to provide an objective comparison of one project with another.

The DQI structures assessment of product qualities according to the three tenets of Western architectural design established by Vitruvius (2001). The DQI format translates Vitruvius’ principles of commodity, firmness and delight into the three indicators of functionality, build quality and impact for use in a modern context (Table 2). These terms, although not a direct translation of Vitruvius' text ${ }^{1}$, provide a useful

\footnotetext{
${ }^{1}$ The phrases commodity, firmness and delight relate to Book 1, Chapter 3, Paragraph 2 of Vitruvius’ work. They were attributed by Henry Wotton in The Elements of Architecture, Pt. 1 (1624). More literal translations of Vitruvius' phrases might be firmitas (durability), utilitas (convenience) and venustas (pleasantness or beauty).
} 
stance from which the agenda of design quality can be advanced in construction and are being adopted by industry. In our framework (Figure 3), the DQI fits into the performance metrics for product quality and business performance.

\section{[TABLE 2]}

The DQI asks stakeholders to assess design quality through a structured questionnaire, administered in a facilitated workshop. Stakeholders express their response to a series of statements describing design qualities (such as: 'The building is sited well in relation to its context') on a Likert scale, generating categorical data. The responses of all stakeholders are summarised in a radar chart (Fig 5).

\section{[FIGURE 5]}

The DQI is currently being piloted in 100 organisations and approaches to its application are being established. The industry has already begun to use the metric to illustrate design quality of products to other parties (Spring, 2002). Dorrell (2000) has noted: "From the outset it has to be clear that the quality in design and construction have to be treated as one, and these indicators are the key.” This could be achieved by periodic use of the DQI during these project phases. It could also help structure design reviews. As such, the DQI could complement subjective judgements of design quality (see CABE (2002b), for example) currently performed without an auditable, objective measurement.

\section{$6 \quad$ Engaging Stakeholders in Design}

\subsection{A Language of Value}

Stakeholders must be involved in the design process so that the values relevant to each construction project can be identified and understood. We should not make assumptions about stakeholders’ requirements or expectations. The importance of this is emphasised by Saxon (2002b):

"What society does not want from its built environment is repetitive, context-ignoring tackiness. However buildings are produced, cultural expectations (Impact Values) will control the acceptability of buildings. Therefore, an improved understanding of cultural and social expectations is vital if the built environment is to have enhanced 'fit' and value.” 
In this sense, buildings are signs of our times. The sophistication of product design solutions must also advance to reflect the growing expectations of customers within an advancing social context. The Kano Curve is widely used in product design to determine which qualities must be provided in a new generation of product design (Baxter, 1995), recognising that qualities aspired to in one generation of product become expected in the next. Once provided they can not be removed in subsequent products without influencing the perception of product value detrimentally.

Najder (1975) commented that “since various people consider different things good, or aesthetically valuable, and use the same national language to express their thoughts, there is ample opportunity for confusion.” Hence, the need for a common language of value in construction projects. This language must be usable by people with different knowledge, expectations and objectives so they can articulate their values. Associated with the adoption of a common language is the need to establish a common culture (Teller, 2001) which, in this case, would be associated with the desire to create and deliver value. Stakeholders may also need help to articulate their values, as they are often not aware of them (Fischhoff, 2000).

\section{2 $\quad$ Managing Value Delivery in Design}

The DQI is concerned with assessing quality in a product, whereas the Managing Value Delivery in Design research project addresses the creation and delivery of value directly through the design process.

We have established that shared values define the groups (such as companies and societies, for example) to which individuals belong. In construction projects, where stakeholders often have markedly different backgrounds and objectives yet must still collaborate to attain a common goal, a set of project values emerge from an ongoing process of negotiation. Apart from value management exercises conducted during project initialisation, little regard is paid to the importance of the dialogue despite its criticality in maintaining stakeholder buy-in.

A dialogue of value delivery will help assemble common, shared project values based on personal values. Stakeholders will probably find that some of their personal values conflict with those in the project system, but as Najder (op. cit.), noted:

“An individual may operate within several different value-systems - for instance, in subordinating his valuations in one field to religious dogmas, in other to political principles, in another still to practical economic considerations.” 
The interpretation of project values as product attributes is a process of delivering a satisficing design solution through a dialogue that iterates between stakeholders. There are two time implications. First, the value dialogue must continue throughout the project so that changes in project values propagate into the objectives and qualities. Secondly, sufficient time must be provided for the sensemaking (Thiry, 2001) activity of stakeholders so each can make a full contribution.

\section{[FIGURE 6]}

Stakeholders will require evidence of the effectiveness of the value dialogue. The DQI could provide such a link (Fig 6) if the assessment is conducted sufficiently frequently that any mismatch of product attributes and values can be addressed before the cost of rework becomes prohibitive. However, stakeholder fatigue may become prominent as the frequency of assessment rises. The development of the DQI format should address this and ensure that stakeholders remain fully committed to its application to provide accurate information throughout the project.

In its current form, the DQI alone would not be sufficient to close the feedback loop between product qualities and project values. A link is required (shaded box in Fig 6) to interpret the DQI assessment relative to the project values. A mismatch would indicate that specific values are inadequately or excessively reflected in the emerging solution, requiring redress in future design activity. The questions posed in the current DQI are unlikely to be sufficiently generic to represent the complete set of project values, objectives and qualities proposed in the value framework. We may need to think in terms of a DQI toolkit which is customised through the value dialogue on each project.

In addition to engaging stakeholders using the DQI, it may be possible to develop internal means of managing value delivery. The identification of appropriate design metrics would allow links between project values and emerging design solution qualities to be documented and monitored. This will require work with stakeholders to identify the product qualities they are reviewing when forming value judgements. Relevant measures could then be defined to complement existing briefing processes. This issue is part of the ongoing research programme.

\subsection{Mapping Value onto the Design Process}

Complexity can be reduced and process transparency improved by modelling the flow of design information (Austin et al., 1999). A means of delivering value could be established if a process model 
also reflected the contributions that individual design tasks make in forming a product's qualities. This could take two forms:

1. design tasks themselves (or the flow of information between them) could be described in terms of their response to project values; or

2. measurements of product/process qualities could identify the response to project values.

The information generated from such an approach could form an important element of a management information system and be presented in a performance dashboard. Just like the digital cockpits that summarise key business information in Executive Information Systems (Tedeschi, 2002), this dashboard would give an overview of project performance in terms of value delivery. The complexity of construction would necessitate an automated system that provides updated information linked to the ongoing dialogue of value delivery (facilitated by the language of value and value framework). This information would identify the relationship between the progression of individual design tasks and the project values which they address. Hence a summary of project status would draw the attention of management to those design tasks not adding value in the emerging design solution.

This design management information could highlight project values relevant to individual design tasks. High value-adding design tasks could thus be identified and given particular attention and, possibly, additional resources.

7

\section{Conclusions}

This paper reviewed the notions of value and quality to establish how they can be effectively related to construction activity. This is essential if we are to create construction products in a way that directly engages customers as determinants of arbiters of value.

We believe that it is important to differentiate between quality, qualities, values and value and appropriate definitions of these terms have been proposed. The first three are effectively means to the end of providing value, which is achieved by appropriately balancing the benefit resulting from an endeavour with the sacrifice required to complete it.

The DQI could have an important role in value delivery. Further development of the DQI has been identified with the recommendation that the focus should be on establishing a process for the periodic 
application of the tool during design and construction. Depending on the nature and audience of this process, the format of the DQI may have to be changed to improve the flexibility of its assessment criteria. This would require a means of linking assessments formatted according to the project stage to monitor performance over time.

We have identified the need for a common value language to engage stakeholders and proposed the format of a value framework. Further research is required to populate this language and establish its application in everyday practice. In addition, the synthesis of project values and their mapping onto design activities that result in product qualities are the subject of current research.

\section{Acknowledgements}

The authors wish to thank the Department of Civil and Building Engineering, Loughborough University, and the supporters of the Managing Value Delivery in Design project: the EPSRC, DTI, Sheppard Robson, AMEC, BAA, Broadgate Estates, CIBSE, CABE, Davis Langdon \& Everest, RICS and RIBA.

\section{References}

Allinson, K. (1997) Getting There by Design: An Architect’s Guide to Design and Project Management, Architectural Press, Oxford.

Austin, S.A. et al. (1999) Analytical Design Planning Technique: A Model of the Detailed Building Design Process. Design Studies Vol. 20, 279-296.

Ashworth, A. and Hogg, K. (2000) Added Value in Design and Construction. Pearson Education, Harlow, UK.

Baxter, M. (1995) Product Design: Practical Methods for the Systematic Development of New Products. Chapman \& Hall, London.

Best, R. and De Valence, G. (1999) Value in Building. In Best, R. and De Valence, G. (eds) Building in Value: Pre-design Issues. Arnold, London, 13-22. 
British Standards Institution (1991) BS 4778-3.1: Quality Vocabulary - Part 3: Availability, Reliability and Maintainability Terms - Section 3.1 Guide to Concepts and Related Definitions. British Standards Institution, London.

British Standards Institution (1997) BS EN 1325-1: Value Management, Value Analysis, Functional Analysis Vocabulary - Part 1. Value Analysis and Functional Analysis. British Standards Institution, London.

British Standards Institution (2000) BS EN ISO 9000: Quality Management Systems - Fundamentals and Vocabulary. British Standards Institution, London.

Burt, M.E. (1978) A Survey of Quality and Value in Building. Building Research Establishment, Watford, UK.

CABE (2001) The Value of Urban Design: A Research Project Commissioned by CABE and DETR to Examine the Value Added by Good Urban Design the Value of Urban Design. Thomas Telford, London.

CABE (2002a) The Value of Good Design: How Buildings and Spaces Create Economic and Social Value. Commission for Architecture and the Built Environment, London.

CABE (2002b) Design Review. Commission for Architecture and the Built Environment, London.

Cargile, J. (1995) Qualities. In Ted Honderich (ed) The Oxford Companion to Philosophy, Oxford University Press, Oxford.

Daniels, S. (2000) Customer Value Management. Work Study Vol 49 No 2, 67-70.

Dell'Isola, A. (1997) Value Engineering: Practical Applications for Design, Construction, Maintenance and Operations. RS Means, Kingston, MA.

Dent, N. (1995) Value. In Ted Honderich (ed) The Oxford Companion to Philosophy, Oxford University Press, Oxford.

Department for Culture, Media and Sport (2000) Better Public Buildings: A Proud Legacy for the Future. The Better Public Buildings Group, Department for Culture, Media and Sport, London. 
Dorrell, E. (2002) Egan’s Follow-up Report Puts Architecture Centre Stage. The Architects’ Journal, 12 September.

Dumond, E.J. (2000) Value Management: An Underlying Framework. International Journal of Operations \& Production Management Vol 20 No 9, 1062-1077.

Evans, R. et al. (1998) The Long Term Costs of Owning and Using Buildings. The Royal Academy of Engineering, London, November.

Fischhoff, B. (2000) Value Elicitation: Is There Anything in There? In Choices, Values and Frames, Kahneman, D. and Tversky, A (eds), Cambridge University Press, Cambridge, 620-641.

Fowler, T.C. (1990) Value Analysis in Design. Van Nostrand Reinhold, New York.

Gale, B.T. (1994) Managing Customer Value: Creating Quality and Service That Customers Can See. The Free Press, New York.

Gann, D.M., et al. (2003) Design Quality Indicators: Tools for Thinking. Building Research \& Information, Design Quality Special Issue, Accepted for publication.

Griseri, P. (1998) Managing Values: Ethical Change in Organisations. MacMillan Business, London Juran, J.M. and Godfery, A.B. (1999) Juran's Quality Handbook (Fifth Edition). McGraw-Hill, New York.

Keeney, R.L. (1988) Building Models of Values. European Journal of Operational Research Vol 37 No 2, 149-157.

Kelly, J. and Male, S. (2002) Value Management. In Best Value in Construction, Kelly et al. (eds).

Blackwell Science, Oxford.

Köhler, W. (1966) The Place of Value in a World of Facts. Liverlight, NewYork.

Lipton, S. (2001) Chairman, Commission for Architecture and the Built Environment. The Independent, 8 February 2001.

Luxton, C. (2002) Speaking in: The Art Show: Not Just Bricks and Mortar. Channel 4 Television, Transmission Date: Saturday 12 October. 
Magrab, E.B. (1997) Integrated Product and Process Design and Development: The Product Realization Process. CRC Press, Boca Raton, New York.

Miles, L.D. (1961) Techniques of Value Analysis and Engineering. McGraw-Hill Book Company, New York.

Najder, Z. (1975) Values and Evaluations. Clarendon Press, Oxford.

Neasby et al. (1999) Value Management. In Building in Value: Pre-Design Issues, Best, R. and De Valence, G. (eds). Arnold, London.

Pirsig, R.M. (1974) Zen and the Art of Motorcycle Maintenance: An Inquiry into Values. Vintage, London.

SAVE International (1997) Value Methodology Standard. SAVE International, Dayton, OH.

Saxon, R (2002a) A Vision for the Construction Industry. $1^{\text {st }}$ Annual Be Conference, London, 27 November.

Saxon, R. (2002b) The Industry 'Formerly Known as Construction: An Industry View of the Fairclough Review. Building Research \& Information, Vol 30 No 5, 334-337.

Spencer, N.C. and Winch, G.M (2002) How Buildings Add Value for Clients. Thomas Telford, London, ISBN: 0727731033.

Spring, M. (2002) Up and Walking. Building, 25 October, 40-45.

Strategic Forum for Construction (2002) Accelerating Change: A Report by the Strategic Forum for Construction Chaired by Sir John Egan. Rethinking Construction, Construction Industry Council, London, ISBN: 1898671281.

Tedeschi, B. (2002) Digital Cockpits Track a Corporation's Performance. The New York Times, 29 July, E-Commerce Report.

Teller, J. (2001) An On-line Glossary as a Way to Foster the Construction of a Common Culture Among Urban Experts, Stakeholders and Decision-makers. Construction Innovation Vol 1, 259-271. 
Thiry, M. (2001) Sensemaking in Value Management Practice. International Journal of Project Management Vol 19, 71-77.

Trischler, W.E. (1996) Understanding and Applying Value-Adding Assessment: Eliminating Business Process Waste. Quality Press, Milwaukee, Wisconsin.

Vickers, G. (1968) Value Systems and Social Process. Tavistock Publications, London.

Vitruvius, (2001) Ten Books on Architecture, Rowland, I.D and Noble Howe, T. (eds) Cambridge University Press, Cambridge, UK.

Womack, J.P. and Jones, D.T. (1996) Lean Thinking. Simon \& Schuster UK, London.

Woodruff, R.B. and Gardial, S.F. (1996) Know Your Customer: New Approaches to Understanding Customer Value and Satisfaction, Blackwell, Cambridge, MA. 


\begin{tabular}{|l|c|}
\hline Cost / Expenditure & Ratio \\
\hline Design Costs & 0.1 \\
Construction Cost & 1 \\
Operations / Maintenance Cost & 5 \\
Business Staffing Cost & 200 \\
Business Income & $250+$ \\
\hline
\end{tabular}

TABLE 1: Ratio of Costs and Expenditures during the Life of a Building (Saxon, 2002a) 


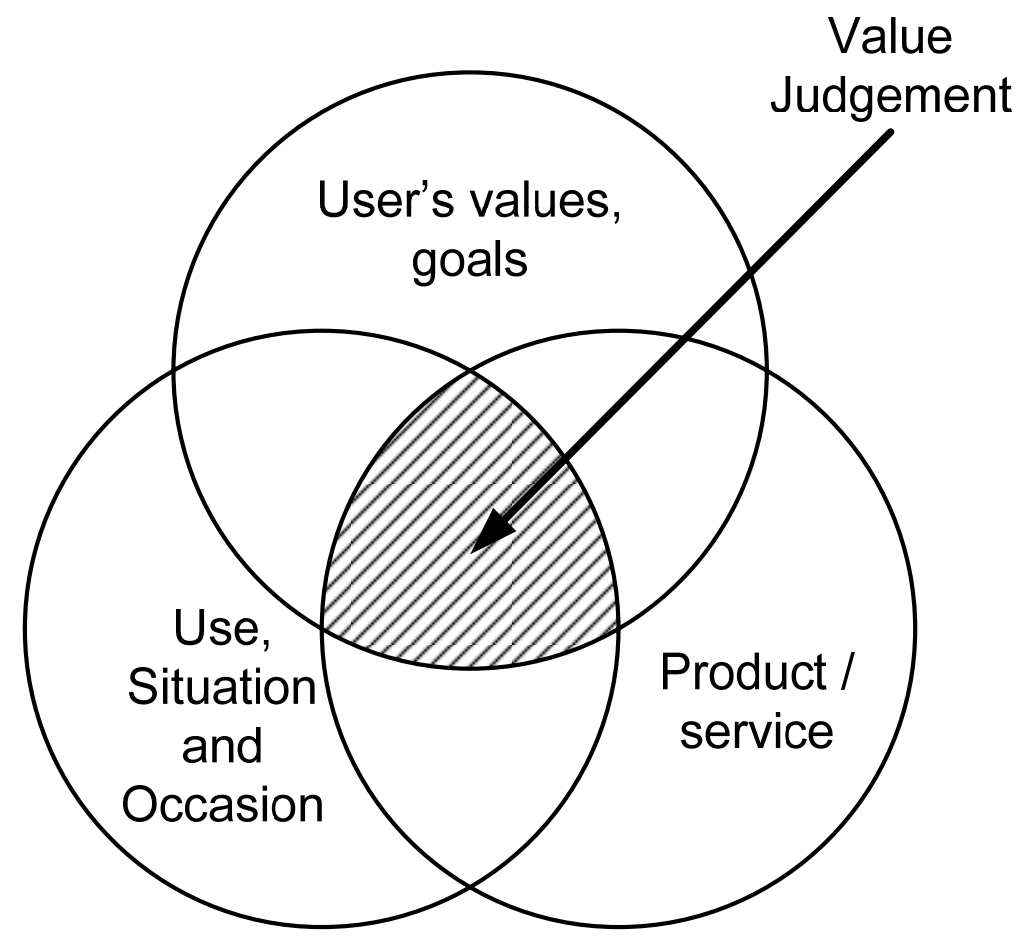

FIGURE 1: Content of Value Judgements (Woodruff and Gardial, 1996) 


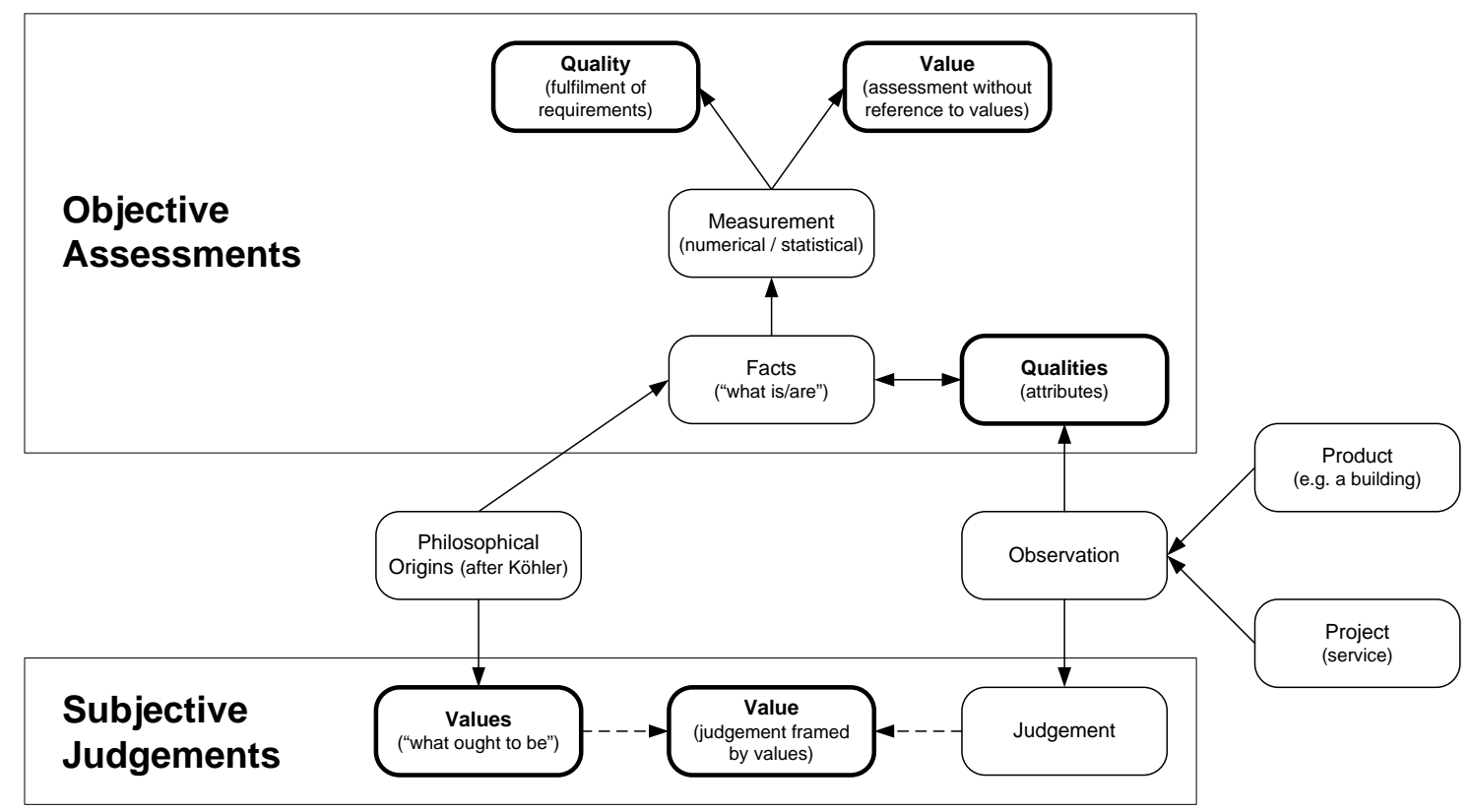

FIGURE 2: Relationships between Quality and Value 


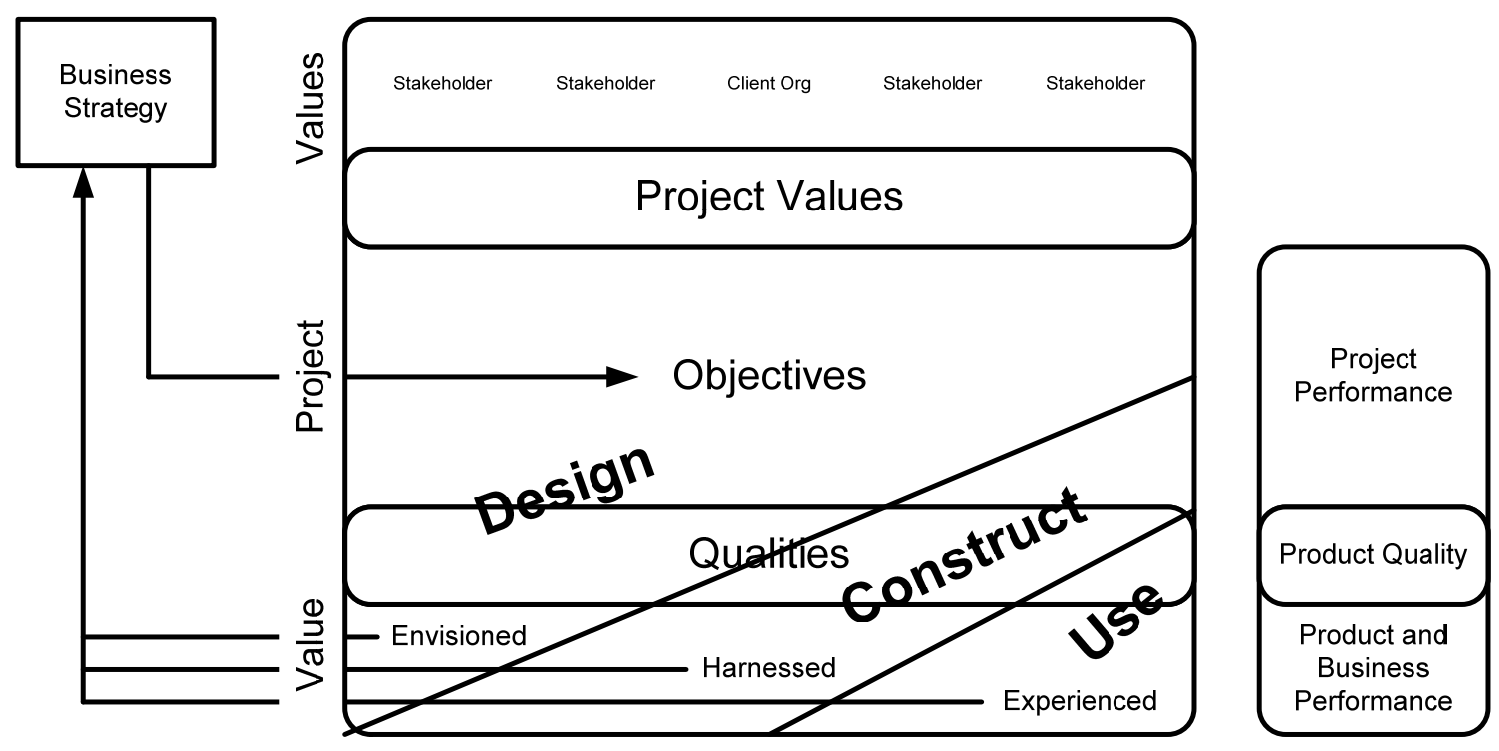

FIGURE 3: Value Translation and Assessment Framework 


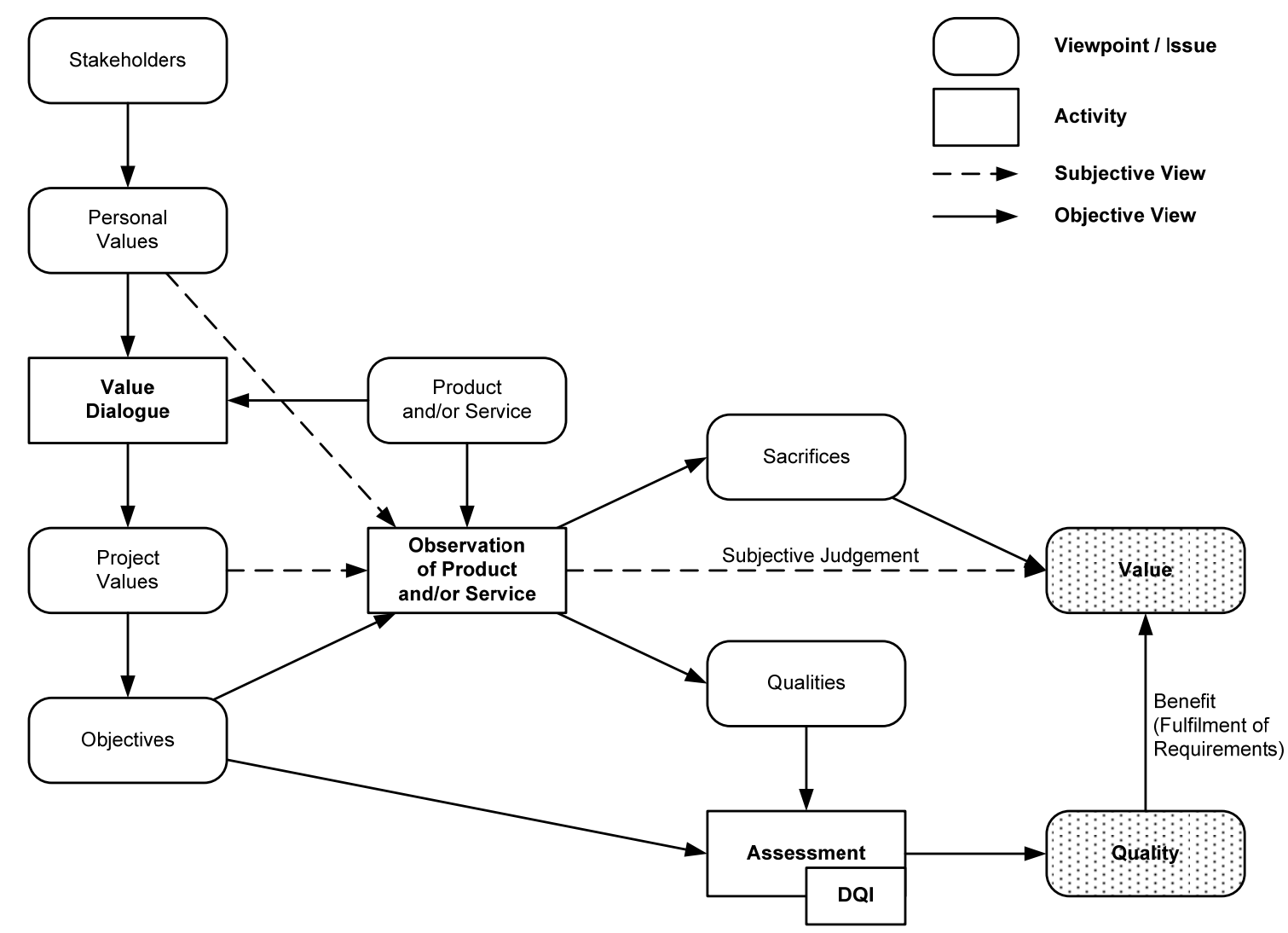

FIGURE 4: Implementation of the Value Framework 


\begin{tabular}{|c|c|c|c|}
\hline DQI Indicator & DQI Assessment Quality Fields & Issue Assessed & Vitruvian Principle \\
\hline Functionality & Use; Access; Space & $\begin{array}{l}\text { Does the product support the required } \\
\text { functions? Does it do what it is } \\
\text { supposed to? }\end{array}$ & Commodity \\
\hline Build Quality & $\begin{array}{l}\text { Performance; Engineering Systems; } \\
\text { Construction }\end{array}$ & $\begin{array}{l}\text { How well is the building built? Will it } \\
\text { fall down? }\end{array}$ & Firmness \\
\hline Impact & $\begin{array}{l}\text { Form \& Materials; Internal } \\
\text { Environment; Urban \& Social } \\
\text { Integration; Character \& Innovation }\end{array}$ & $\begin{array}{l}\text { How beautiful is the building? Does it } \\
\text { excite the people who use it, making } \\
\text { them want to be in or around it? }\end{array}$ & Delight \\
\hline
\end{tabular}

TABLE 2: Relationship of DQI Quality Fields to Vitruvian Principles 


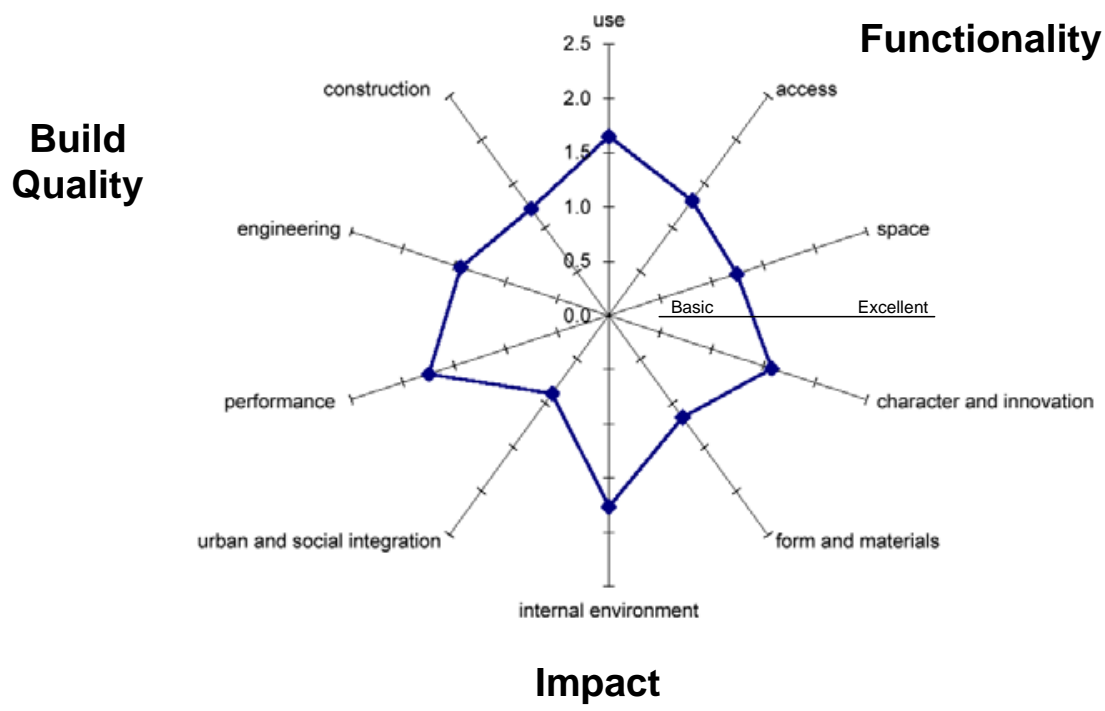

FIGURE 5: Example DQI Assessment 


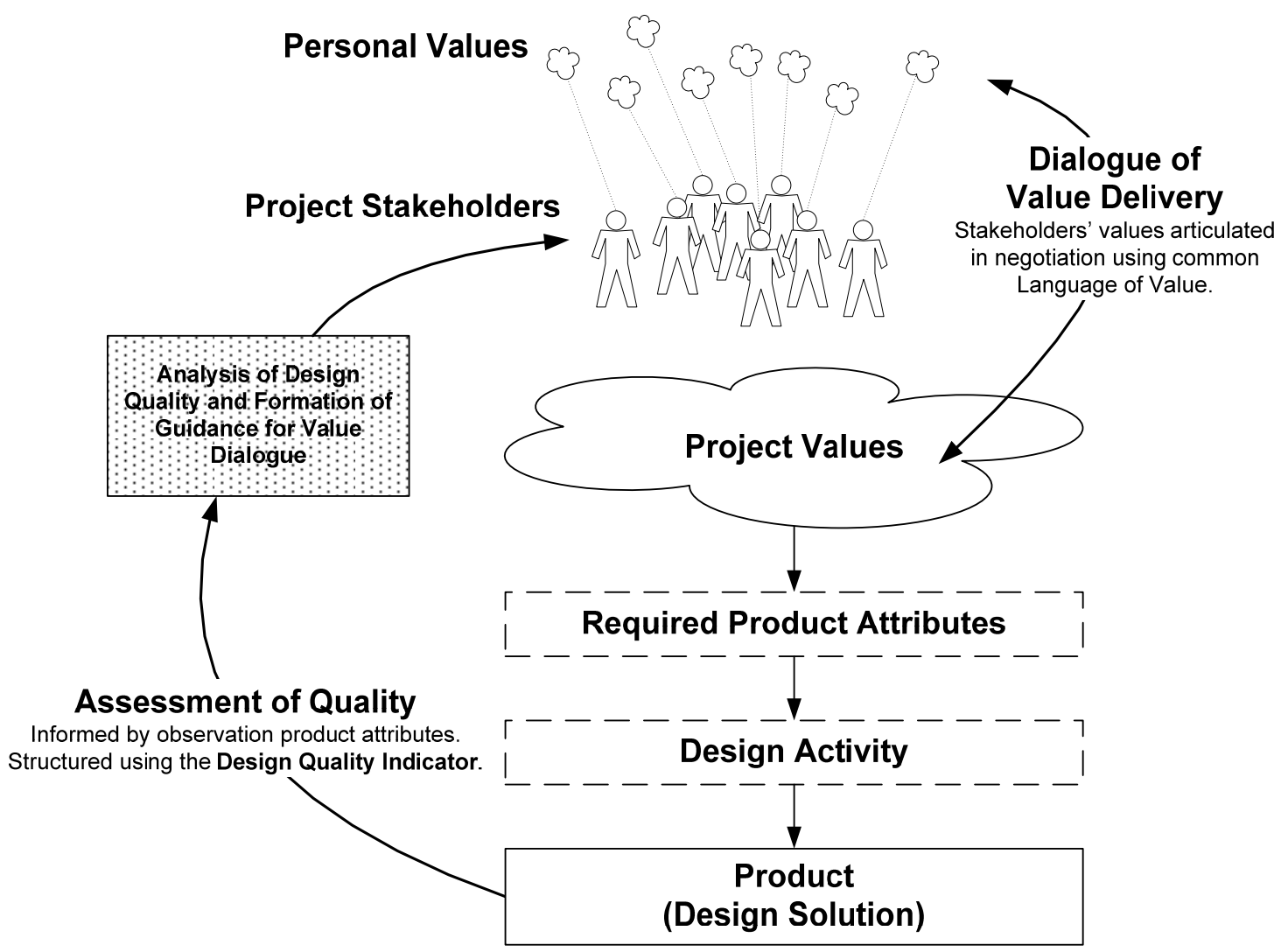

FIGURE 6: Role of the DQI in the Value Dialogue 